\title{
Review Article \\ Convection-Enhanced Delivery in Malignant Gliomas: A Review of Toxicity and Efficacy
}

\author{
Minghan Shi iD ${ }^{1}$ and Léon Sanche ${ }^{2}$ \\ ${ }^{1}$ Department of Radiation Oncology, The Second Affiliated Hospital of Zhejiang University, School of Medicine, Hangzhou, China \\ ${ }^{2}$ Department of Nuclear Medicine and Radiobiology, Université de Sherbrooke, Sherbrooke, QC, Canada \\ Correspondence should be addressed to Minghan Shi; minghan_shi@zju.edu.cn
}

Received 14 March 2019; Revised 6 May 2019; Accepted 25 June 2019; Published 22 July 2019

Academic Editor: Claudio Festuccia

Copyright (c) 2019 Minghan Shi and Léon Sanche. This is an open access article distributed under the Creative Commons Attribution License, which permits unrestricted use, distribution, and reproduction in any medium, provided the original work is properly cited.

\begin{abstract}
Malignant gliomas are undifferentiated or anaplastic gliomas. They remain incurable with a multitude of modalities, including surgery, radiation, chemotherapy, and alternating electric field therapy. Convection-enhanced delivery (CED) is a local treatment that can bypass the blood-brain barrier and increase the tumor uptake of therapeutic agents, while decreasing exposure to healthy tissues. Considering the multiple choices of drugs with different antitumor mechanisms, the supra-additive effect of concomitant radiation and chemotherapy, CED appears as a promising modality for the treatment of brain tumors. In this review, the CEDrelated toxicities are summarized and classified into immediate, early, and late side effects based on the time of onset, and local and systemic toxicities based on the location of toxicity. The efficacies of CED of various therapeutic agents including targeted antitumor agents, chemotherapeutic agents, radioisotopes, and immunomodulators are covered. The phase III trial PRECISE compares CED of IL13-PE38QQR, an interleukin-13 conjugated to Pseudomonas aeruginosa exotoxin A, to Gliadel ${ }^{\circledR}$ Wafer, a polymer loaded with carmustine. However, in this case, CED had no significant median survival improvement (11.3 months vs. 10 months) in patients with recurrent glioblastomas. In phase II studies, CED of recombinant poliovirus (PVSRIPO) had an overall survival of $21 \%$ vs. $14 \%$ for the control group at 24 months, and $21 \%$ vs. $4 \%$ at 36 months. CED of Tf-diphtheria toxin had a response rate of $35 \%$ in recurrent malignant gliomas patients. On the other hand, the TGF- $\beta 2$ inhibitor Trabedersen, HSV-1-tk ganciclovir, and radioisotope

${ }^{131}$ I-chTNT-1/B mAb had a limited response rate. With this treatment, patients who received CED of the chemotherapeutic agent paclitaxel and immunomodulator, oligodeoxynucleotides containing CpG motifs (CpG-ODN), experienced intolerable toxicity. Toward the end of this article, an ideal CED treatment procedure is proposed and the methods for quality assurance of the CED procedure are discussed.
\end{abstract}

\section{Introduction}

Despite the fast development of several modalities for cancer treatment, such as chemotherapy, immunotherapy, and targeted therapy, pharmaceutical agents available for brain tumor treatment remain rare. The failure of the application of these agents in brain tumor is partially due to the existence of the blood-brain barrier (BBB), which prevents them from entering the tumor site. This problem led to the development of strategies to open temporarily the $\mathrm{BBB}$, including osmotic and ultrasonic BBB disruption [1-4]. During the osmotic BBB disruption procedure, hyperosmotic agents such as mannitol are infused and a temporary cell membrane retraction is induced, creating a physical opening between the endothelium cells [1-3]. In the case of ultrasonic BBB disruption, pulsed ultrasound is applied in combination with infusion of microbubbles to disrupt the $\mathrm{BBB}$, thus increasing the intratumoral concentration of the therapeutic agents [4]. Rather than disrupting the $\mathrm{BBB}$, another strategy consists of bypassing the BBB. In the early 1990s, Oldfield and his research team proposed a new technique to traverse the $\mathrm{BBB}$, convection-enhanced delivery (CED) [5], by which interstitial infusion of the agent by a syringe pump creates a pressure gradient, permitting enhanced distribution of the brain. The technical parameters of the CED procedure have been reviewed by Allard E. et al. [6]. 
With the emergence of novel radiation therapy techniques, such as intensity-modulated radiation therapy (IMRT), volumetric-modulated arc therapy (VMAT), and $4 \pi$ radiation therapy (RT) [7], the precision of target volume delineation has largely improved, which in some aspects could make CED of therapeutic agents less attractive. However, the rationale behind CED remains a potentially useful way to enhance drug delivery to the brain. Besides increased tumor uptake of antitumor agents, by penetration of the BBB [8], the localization of the drug provides an effective condition for concomitant chemoradiation therapy and the benefits of its supra-additive effect $[8,9]$.

\section{Preclinical Studies}

In animal studies, two delivery systems were commonly employed for safety and efficiency evaluation. (1) A micro infusion syringe connected to a micro infusion pump: Our group optimized this technique by using flat tip $33 \mathrm{Ga}$ needle gas-tight Hamilton syringe, to inject $10 \mu \mathrm{L}$ of therapeutic agent at an infusion rate of $0.5 \mu \mathrm{l} / \mathrm{min}$, for a duration of 20 mins [8]. These parameters prevented reflux from the injection site, permitting a large distribution volume in the tumor site of a rat brain. (2) An ALZET ${ }^{\circledR}$ osmotic pump, a device embedded subcutaneously: It provides an infusion time of up to a week $[10,11]$ and hence has the advantage of long-term infusion without recurrent operations. The longer infusion time means less reflux and a larger diffusion volume, which is a key parameter for brain tumor CED in humans. Since the brain volume of a rat at 8 weeks is only $\sim 600 \mathrm{~mm}^{3}$ [12], the difference in the distribution volume, after 20 mins infusion, with a syringe or an osmotic pump can be indistinguishable. Yang et al. compared survival after CED injection of carboplatin in F98 glioma bearing rats with a syringe, to that obtained with an ALZET $^{\circledR}$ osmotic pump. The median survival time (MeST) for controls was 23 days after cell implantation. CED of carboplatin with the syringe extended the MeST to 46 days, whereas the ALZET $^{\circledR}$ osmotic pump further increased it to 59 days. However, the osmotic pump delivered $84 \mu \mathrm{g}$ of carboplatin, as opposed to $20 \mu \mathrm{g}$ by the CED with the syringe [13], suggesting that prolonged administration is therapeutically more effective.

In experimental studies, catheter design plays an important role in reducing the reflux of the infusate and increasing the convection volume [14]. The most common is the one port catheter, which consists of a cannula with one port at the tip. This catheter has been well studied in gels and is widely used in animal studies [15-17]. The computational and experimental studies in gels and rats showed that reflux decreases as the diameter of the needle decreases $[15,18,19]$. Thus, to prevent reflux within the catheter, a diameter smaller than $30 \mathrm{Ga}$ was usually chosen, which limited the flow rate to $0.5 \mu \mathrm{L} / \mathrm{min}$ $[20,21]$. To further reduce reflux, Krauze and his colleagues designed a stepped cannula [22]. Compared to a simple 32 gauge needle, the step-design cannula was able to increase the reflux-free flow rate from $5 \mu \mathrm{L} / \mathrm{min}$ to $50 \mu \mathrm{L} / \mathrm{min}$ in agarose gel and from $0.5 \mu \mathrm{L} / \mathrm{min}$ to $<50 \mu \mathrm{L} / \mathrm{min}$ in the rat brain
$[15,17,19]$. To increase the distribution volume, multiple-pore catheter was designed. It has five pores of $0.2 \mathrm{~mm}$ diameter on opposite sides of the tip [23]. Computational analysis predicted that the drug distribution from the multiple pores design in the caudate nucleus increased the distribution volume by $26 \%$. However, an experimental study with this type of catheter in gels has shown that the infusate can only be released from the proximal pores leaving the rest of the pores useless [24]. Another design increased the distribution volume by using a hollow fiber catheter, with millions of nanoscale pores $(450 \mathrm{~nm})$ [25]. Seunguk and his colleagues found that the distribution volume of a dye injected in a gel by such a hollow fiber catheter was 2.7 times larger than that obtained with a one port catheter. However, further studies are required for clinical applications, because longer catheters would be required in humans, and the physical characteristics of the drug distribution may change. In clinical settings, before the administration of chemotherapy, a cavity is left by tumor resection, which makes the administration of a chemotherapeutic agent by CED complicated. To alleviate the problem, a balloon-tipped catheter with an inflatable balloon attached to the tip of the catheter was designed. The inflatable balloon fills the resection cavity and thus reduces reflux [26, 27].

Halle et al. systemically reviewed preclinical CED studies and found that methodological parameters such as catheter design, infusion rate, and infusion duration varied among different studies. Data on endpoint measurements of drug diffusion and adverse effects are often missing in many preclinical studies [28]. These parameters are crucial for carrying out preclinical investigations and further clinical studies based on promising results from animal experiments. The authors also suggested that in vivo studies with larger animal brains should be carried out before undertaking clinical trials.

Besides the different techniques employed in CED, different types of medications have been tested: chemotherapeutic drugs, antibodies, toxins, vaccines, etc. The standard treatment of glioblastomas (GBM), the most common and aggressive glioma in adults, is composed of several combined modalities, which may include surgery, RT, concomitant and adjuvant temozolomide (TMZ) chemotherapy, and more recently alternating electric field therapy. The current standard treatment includes concurrent and adjuvant TMZ chemotherapy and it is therefore reasonable to compare CED with this agent in preclinical studies. Saito et al. in 2004 studied CED delivery of tumor necrosis factor-related apoptosis-inducing ligand (TRAIL) and systemic delivery of TMZ in a U87MG intracranial xenograft rat model [29]. Both CED of TRAIL and systemic delivery of TMZ increased survival. More importantly, the synergistic effect of the chemotherapeutic agent cisplatin and TRAIL has been demonstrated in a glioma model. In this study, a combination of CED of TRAIL with systemic delivery of TMZ further increased the survival $(P=0.032)$ [30]. Barth and his research team in 2011 studied RT plus oral delivery of TMZ in daily doses of $80 \mathrm{mg} / \mathrm{kg}$ body weight for $5 \mathrm{~d}$ or CED of $1.5 \mathrm{mg} \mathrm{TMZ}$ in $15 \mu \mathrm{L}$ at a flow rate of $0.5 \mu \mathrm{L} / \mathrm{min}$ for 30 min in F98 glioma bearing Fischer rats [13]. Radiation 
was performed at 6,7 , and 8 days after implantation with a daily dose of $5 \mathrm{~Gy}$. They obtained an MeST of 23 days for oral TMZ plus radiation and 27 days for CED of TMZ plus radiation, compared to 21 days for radiation alone. Although a modest increase of MeST in the CED group was observed, no significant difference was found. Indeed, due to its inherent ability for crossing the BBB, TMZ may not be a good candidate for CED and the study of Barth and his research group confirmed this hypothesis. Other studies focused on a nanocarrier for the delivery of TMZ by CED, i.e., the polymeric nanoparticle vector [31], TMZloaded photopolymerizable PEG-DMA-based hydrogel [32], and liposomes [33]. They all demonstrated various degrees of antitumor efficacy compared to free TMZ or reduced toxicity to normal brain, but failed to demonstrate the advantage of CED of TMZ over oral delivery of TMZ, which is the standard method of administration in the clinic.

The well-studied chemotherapeutic agents by CED are platinum-based drugs, such as cisplatin, carboplatin, and oxaliplatin, delivered in glioma bearing rats which were largely investigated by the groups of Barth and Elleaume [11, 13, 20, 21, 34-36], Lonser [17], Tomita [37], and ours $[8,38,39]$. These authors measured the combined effect of radiation and platinum drugs. However, due to differences in tumor model, doses of infusion, and protocol design, the effectiveness of these drugs cannot be determined from a comparison of the results of the different groups. Moreover, CED of these drugs was not compared to other routes of delivery such as intra-arterial injection and intravenous infusion. For this reason, in our laboratory, we performed a series of studies comparing intravenous (iv), intra-arterial (ia), and CED of different platinum drugs, as well as their combinational effect with radiation [8,39-41]. It was further observed that carboplatin was the most effective platinum drug compared to cisplatin and oxaliplatin. When encapsulated within a liposome, carboplatin still had the advantage over the others; however, the other platinum drugs were not encapsulated nor designed for CED.

There are four main theories regarding the mechanisms of the synergistic action of platinum drugs and radiation: radiation sensitization of the hypoxic cells by platinum drugs [42-45]; fixing by platinum drugs of the radiationinduced sublethal DNA damage [46, 47]; radiation-induced formation of toxic platinum adducts [48, 49]; and direct radiation sensitization by platinum drugs [50-54].

Tippayamontri et al. studied the amount of DNAplatinum adducts formed in the nucleus of cancer cells over time, both in vitro and in vivo. The efficiency of RT was found to be proportional to the amount of the $\mathrm{Pt}$ drug bound to the DNA of the cancer cells. When mice bearing a human colorectal HCT116 tumor were irradiated at the time of highest yields of DNA-platinum adducts, the synergy between radiation and cisplatin or oxaliplatin and their liposomal formulation was the largest $[55,56]$. Based on their findings, CED of these agents was carried out to further increase tumor uptake. However, survival increase of F98 glioma bearing Fisher rats was not significant. This may reflect the ceiling of radiation enhancement based on DNAplatinum yield [8].

\section{Clinical Studies}

3.1. Clinical Protocols. Before carrying out clinical trials with CED, a carefully designed clinical protocol is surely a prerequisite to achieve significant results, especially for new treatment techniques, where many parameters need to be adjusted from animal to human protocols. The catheter designs and placement, flow rate, choice of therapeutic agent, infusion volume, and visualization of the infusion volume are all key parameters that need to be accurately assessed. Considering the problems encountered in the setting of these parameters, but not limited to them, the PRECISE phase III clinical trial failed to demonstrate an advantage of CED over standard-of-care treatment [57].

Ren et al. in 2003 designed and published a phase I/II protocol of CED of a liposomally encapsulated replicationdisabled Semliki Forest virus vector, carrying the human interleukin 12 gene (LSFV-IL12). This protocol involved treatment of recurrent or progressive GBM to evaluate the safety, maximum tolerated dose (MTD), and antitumor efficacy [58]. They designed an infusion volume of $11 \mathrm{~mL}$ at a maximum infusion rate of $0.5 \mathrm{~mL} / \mathrm{h}$ for a total of $24 \mathrm{~h}$. However, the results of this study were not further analyzed and disseminated.

Another phase I clinical trial protocol was proposed by White et al. in 2012, after a series of successful animal studies of CED of carboplatin [59]. The principal research objectives were to determine the safety, tolerability, and MTD, via dose escalation and further facilitate the safe application of a phase II protocol. In addition, the efficacy, carboplatin distribution, and visualization of infusate will also be evaluated with a carboplatin delivery of $8 \mathrm{~h} / \mathrm{d}$ for 3 consecutive days at a maximum infusion rate of $0.6 \mathrm{~mL} / \mathrm{h}$ for no more than $20 \mathrm{~mL}$ of infusate per day.

3.2. Toxicity Studies in Clinical Trials. The safety and tolerability of various therapeutic agents, including antibodies, targeted toxins, interleukins, chemotherapeutic drugs, targeted radioisotopes, and vaccines (Table 1), have been studied in clinical trials in the last two decades.

Based on their results of intratumoral injection of monoclonal antibodies in patients with advanced malignant glioma, Wersall et al. classified side effects as immediate $(<2 \mathrm{~h})$ or late $(5-48 \mathrm{~h})$ and we believe that CED could have a similar evolution [60]. On the other hand, Kunwar S. et al. defined three phases of toxicity based on the time of onset: pre-CED, peri-CED, and post-CED [61]. Here, based on their classifications and the review of all published CED clinical trials, we reclassify CED-related toxicities as immediate, early, and late side effects.

(a) Immediate side effects occur within hours of the placement of catheters. Physical damage to the brain tissue and cerebral hemorrhage by the catheter are possible causes related to symptoms such as headache, seizure, and neurological toxicities [61].

(b) Early side effects occur hours to days after CED. Mechanical stress caused by the infusion of fluid leads to common complaints such as headache, seizure, worsening of neurological symptoms, shivering, and mild fever $[62,63]$. 


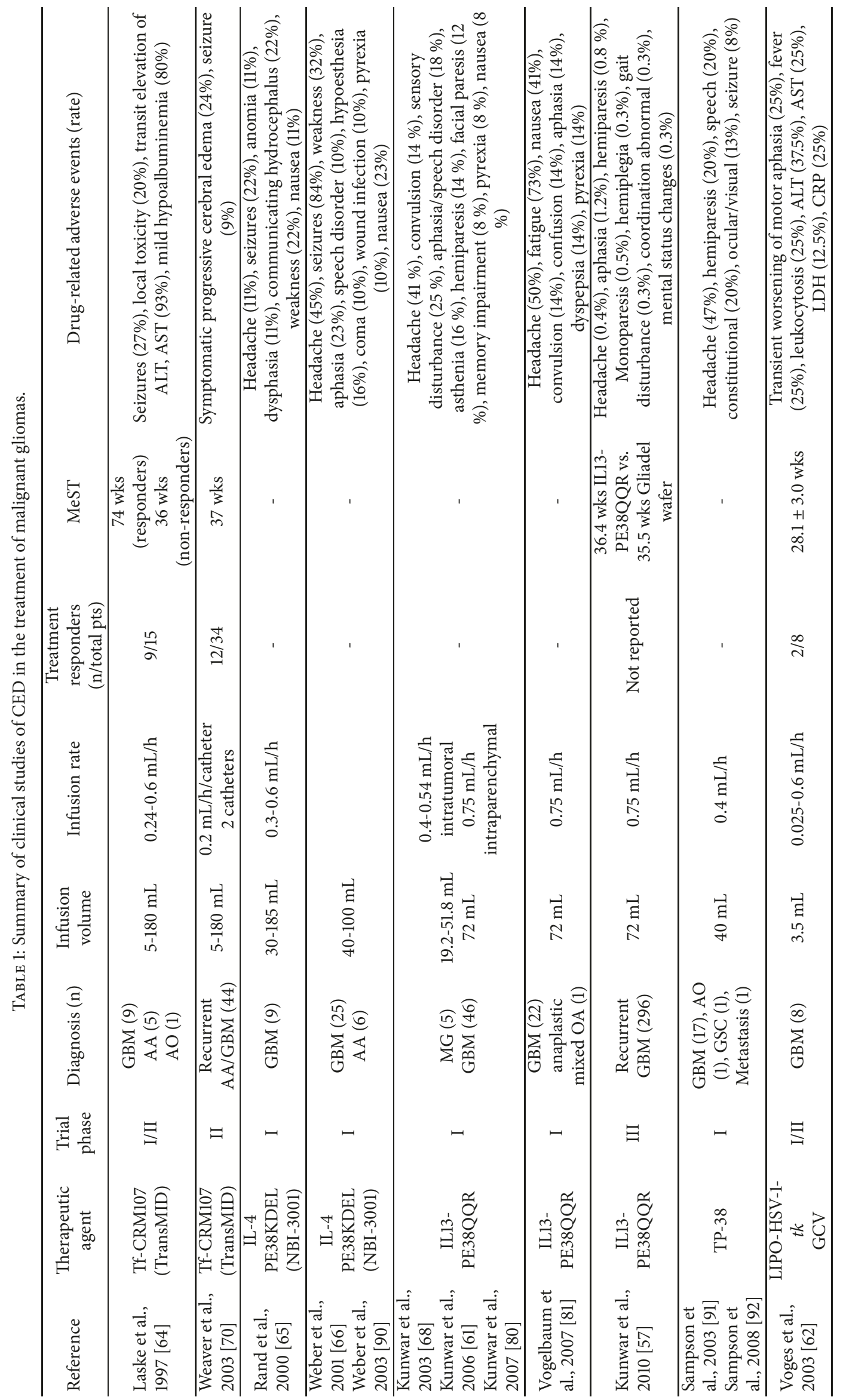




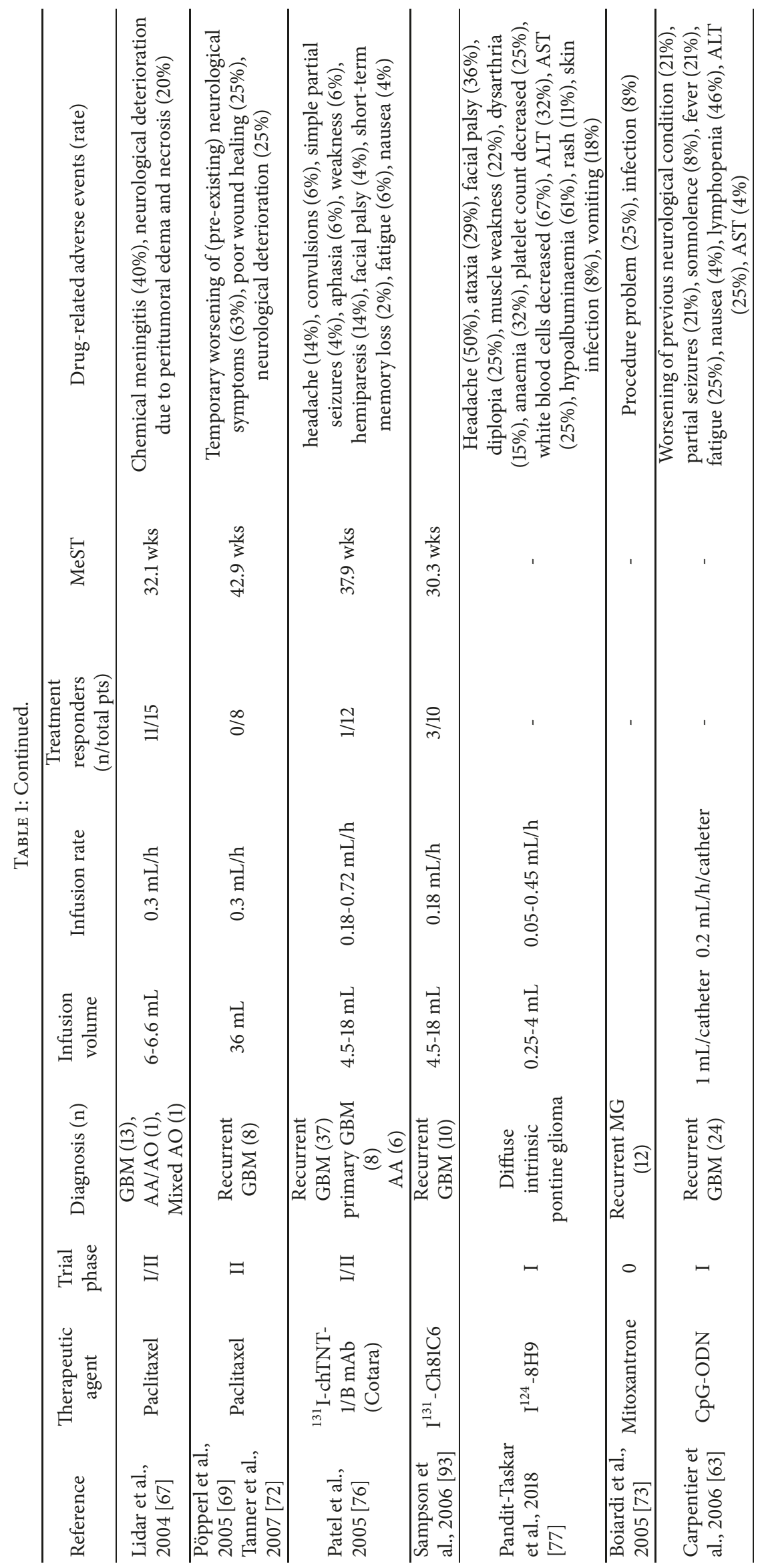




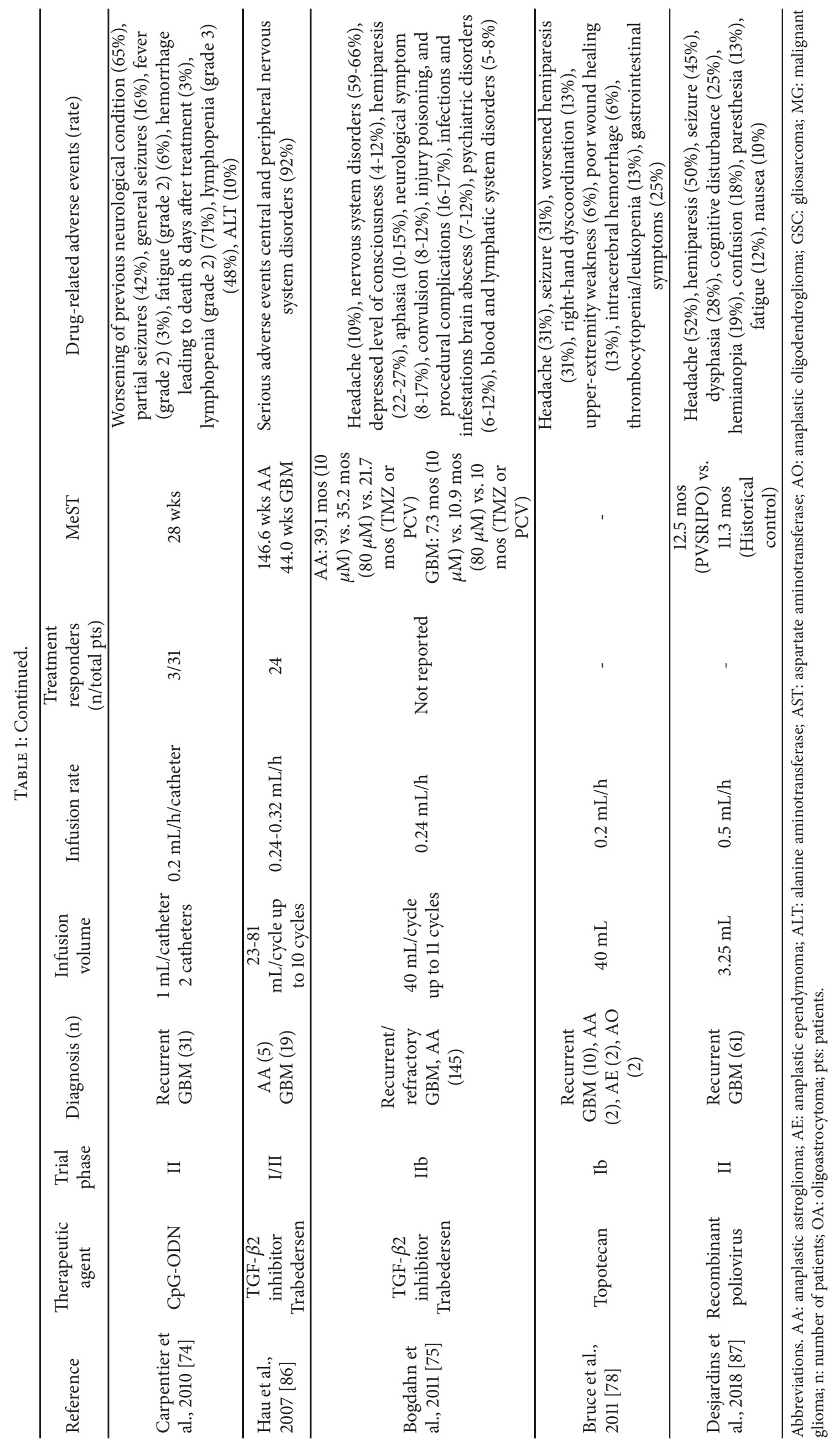


(c) Late side effects include mainly neurological toxicity, due to the toxicity from delivered drugs, occurring days to weeks after infusion [64-67].

Depending on the location of the toxicities related to CED, we summarized them into two categories.

(a) Local Toxicities (Common and Severe). These comprise neurological toxicities due to inflammatory reactions, necrosis, and peritumor edema [64]. Depending on the location of the tumor and site of infusion, patients could manifest different types of neurological toxicity symptoms: headache, seizure, nausea, pyrexia, sensory disturbance, upper motor neuron lesion, aphasia/speech disorder, and memory impairment [68]. The reaction can be severe and cannot be satisfactorily controlled by steroids, and debulking is needed to reduce the mass effect [65]. In the study by Rand et al., nine patients received $30-185 \mathrm{~mL}$ of IL-4(3837)-PE38KDEL and seven of them required craniotomy due to uncontrollable cerebral edema. The reaction seems not related to the infusion rate, infusion volume, total infused dose, and number of catheters. The edema appeared 10-97 days after CED procedure; thus, it was not procedure-related. However, edema could be well controlled by steroids [64, 69] in other trials. In the procedure of Weaver and Laske, $5-180 \mathrm{~mL}$ of Tf-CRM107, a targeting toxin, was infused in patients with anaplastic oligodendroglioma (AO)/anaplastic astroglioma (AA)/GBM. The symptoms related to the edema and mass effect were fewer (i.e., 3 in 44 treatments) and well controlled by steroids and hyperosmolar therapy. Their phase II clinical trial demonstrated a similar toxicity and showed that cerebral edema can be well controlled by medical treatment [70]. With a similar pretreatment and treatment conditions, such large differences in the rate and severity of local toxicity can only be explained by the infused agent.

Local infection is related to the placement of the catheter and infusion time. Klatzmann et al. identified the pathogens to be gram negative and staphylococcus bacteria, due to the catheter and CSF leak to the skin. These infections were controllable with antibiotics $[67,69,71-75]$. Complications such as subdural empyema and bacterial meningitis were diagnosed in the study by Lidar et al. [67]. Chemical meningitis happens when chemotherapeutic agents, such as Taxol, reflux from the infusion site (i.e., $40 \%$ of patients experienced chemical meningitis) [67].

(b) Systemic Toxicities (Rare and Transitory). Studies with TP38 or IL13, IL4, and Trabedersen did not show any systemic toxicity. General toxicities expressed as fever, fatigue, and erythema were observed $[74,76,77]$, as well as gastrointestinal symptoms (nausea, vomiting) [76-78]. Hematological changes (decreased WBC, platelet, lymphopenia [63, 77, 78]) and liver enzyme perturbations (elevated AST, ALT, LDH, CRP, hypoalbuminemia $[63,64,74,77]$ ) were also observed.

3.3. Efficacy Studies in Phase II and Phase III Clinical Trials. The efficacy of CED clinical studies in GBM treatments was reviewed by Jahangiri in 2017 [79]. Our section includes, in addition to all clinical trials reviewed by this author, more recent ones published after 2017 and those related to other malignant gliomas.

\subsubsection{Targeted Antitumor Agents}

Tf-CRM107 (TransMID) (Tf-Diphtheria Toxin) [64, 70]. This agent is a human transferrin, which targets receptors on the surface of tumor cells fused to a diphtheria toxin. In the phase I/II study of Laske group, out of 15 evaluated recurrent malignant gliomas patients, seven had partial response (PR) and two even had a complete response (CR) to Tf-CRM107 with a dose of $0.5-199 \mu \mathrm{g}$ per treatment at a maximum infusion rate of $0.24-0.6 \mathrm{~mL} / \mathrm{h}$, giving a total volume of 5$180 \mathrm{~mL}$. The tumor response appeared to be dose-dependent, with two out of five of the evaluated patients having PR at the dose of $0.5-12.8 \mu \mathrm{g}$, while in the higher dose groups, seven patients out of 10 had PR or even CR. Thus, the same group carried out the phase II study at a total dose of $26.8 \mu \mathrm{g}$ per treatment, at an infusion rate of $0.4 \mathrm{~mL} / \mathrm{h}$, for a total of $40 \mathrm{~mL}$. In the 34 evaluated patients, five patients had CR, seven had PR, which was a $35 \%$ response rate. However, all patients enrolled had a progressive disease and the progression of 9 of them was halted due to the response to treatment. Moreover, the magnetic resonance imaging (MRI) response rate was correlated with the survival analysis, with a median survival of 37 weeks. Due to these encouraging results, a phase III clinical trial of recurrent GBM was planned.

IL13- PE38QQR [57]. This agent is a human interleukin13 (IL13) conjugated to a modified form of Pseudomonas aeruginosa exotoxin A (PE38QQR). The tolerable toxicity profile and efficacy over control groups, demonstrated by a series of phase I studies, led to the design of a phase III trial, also known as the PRECISE trial [61, 68, 80, 81]. It compared survival of CED of IL13-PE38QQR with tumor cavity placement of Gliadel ${ }^{\circledR}$ Wafer (GW). There were 296 recurrent GBM patients recruited; 192 were assigned to the CED group and 104 to the GW group. Infusion was performed at rate of $0.75 \mathrm{~mL} / \mathrm{h}$ for 96 hours with a concentration of $0.5 \mu \mathrm{g} / \mathrm{mL}$, which is the MTD assigned from safety studies. Unfortunately, of the patients evaluable for efficacy, the median survival for the CED group was 11.3 months compared to a median survival of 10 months in the GW group. No statistical significance was found $(\mathrm{P}=0.310$; hazard ratio $0.81 ; 95 \% \mathrm{CI}=0.67$ 1.18).

The underlying reason of the failure of this multicenter study was further analyzed [82]. Catheter positioning data were retrieved and the distribution volume of the infusate was predicted through iPlan ${ }^{\circledR}$ Flow software from Brainlab. The prediction showed that only $20.1 \%$ of peritumoral area was covered by IL13- PE38QQR. However, the effect size of the catheter score and the number of optimally positioned catheters on PFS are small. Thus, before carrying out further clinical protocols, the technical problems must be solved and quality control must be first assured, especially the optimization of parameters, such as geometry of the infusion 
catheter, flexibility of protocol, and determination of drug distribution.

HSV-1-tk GCV [71, 83-85]. This regimen was a two-step treatment modality. Herpes simplex virus thymidine kinase (HSV-tk) gene was first transduced to the glioblastoma cells by either intratumoral injection or CED, then ganciclovir (GCV) was delivered systemically. Several investigations with intracerebral infusion of HSV-1-tk failed to demonstrate survival benefits due to limited diffusion volume of HSV-1-tk. Later in 2003, Voges et al. designed a liposome encapsulated HSV-1-tk and delivered it through CED with the expectation of an augmented distribution volume [62]. Unfortunately, it was not the case: their large and positively charged liposomes remained at the site of infusion, as observed in our recent study [39]. As a result, only two patients out of eight had PR.

TGF- $\beta 2$ Inhibitor Trabedersen (AP 12009) $[75,86]$. This compound is a transforming growth factor 2 (TGF- $\beta 2$ ) inhibitor. It was evaluated in 145 recurrent/refractory AA/GBM patients by Bogdahn et al. Patients were assigned to 2 different dose groups, $2.48 \mathrm{mg}$ for $10 \mu \mathrm{M}$ group and $19.81 \mathrm{mg}$ for $80 \mu \mathrm{M}$ group at an infusion rate of $0.24 \mathrm{~mL} / \mathrm{h}$ for 7 days [75]. In the subgroup analysis, compared to conventional chemotherapy (TMZ or procarbazine/CCNU/vincristine (PCV)), Trabedersen increased the MeST of the AA subgroup from 21.7 months with conventional chemotherapy to 39.1 months (but not significant); similar MeST CED and conventional chemotherapy were also obtained from the GBM subgroup.

Recombinant Poliovirus (PVSRIPO) [87]. This is an attenuated poliovirus type 1 vaccine. Poliovirus receptor CD115 is expressed in glioblastoma and the recombinant poliovirus can recognize CD115 and infect the tumor cells creating a cytotoxic effect. Sixty-one recurrent GBM patients were recruited in this phase II trial, during which, PVSRIPO was infused at a rate of $0.5 \mathrm{~mL} / \mathrm{h}$ for 6.5 hours. The results were compared to a historical control group of 104 patients. Although no significant improvement of the median survival time was observed for CED of PVSRIPO (12.5 months) compared to the control group (11.3 months), the survival of the PVSRIPO group reached a plateau starting at 24 months. The overall survival at 24 months is $21 \%$ for CED of PVSRIPO vs. $14 \%$ for control group, and at 36 months it is $21 \%$ vs. $4 \%$. Moreover, two of them had survived over 69 months after infusion. Thus, further investigations on this vaccine are warranted.

\subsubsection{Chemotherapeutic Agent}

Paclitaxel [67, 69, 72]. This agent is a conventional chemotherapeutic drug that interferes with microtubules during cell division. Its antitumor effects on brain tumors have been reported in preclinical studies. Since it does not pass the BBB, it was considered as an interesting compound for treatment via CED. In the study by Lidar et al., 11 out of 15 patients had either PR or CR. The distribution volume after CED was confirmed by diffusion-weighted MRI (DW-MRI).
They infused paclitaxel $3.6-7.2 \mathrm{mg} /$ day for 5 days at an infusion rate of $0.3 \mathrm{~mL} / \mathrm{h}$. However, $40 \%$ of patients had chemical meningitis and $20 \%$ had neurological deterioration. Another group performed a similar study but followed with 18F-fluoro-ethyl-tyrosine-positron emission tomography (18F-FET-PET) $[69,72]$. They employed similar parameters as Lidar et al., i.e., a total dose of $18 \mathrm{mg}(0.5 \mathrm{mg} / \mathrm{mL})$ or $9 \mathrm{mg}$ $(0.25 \mathrm{mg} / \mathrm{mL})$ at an infusion rate of $0.3 \mathrm{~mL} / \mathrm{h}$ for 120 hours. Six out of eight patients had a temporally stable disease. They also demonstrated that FET-EPT is better than MRI to follow-up patients and that an increase in FET uptake almost always implies a recurrence of the tumor.

\subsubsection{Radioisotopes}

${ }^{131} I$-chTNT-1/B $m A b$ (Cotara) [76]. This compound is a ${ }^{131}$ I-labeled chimeric monoclonal antibody that targets the intracellular antigen histone $\mathrm{H} 1$, which is exposed in the necrotic core of gliomas. In a phase II clinical trial, 39 patients were recruited, but only 12 recurrent glioblastoma patients who had received a dose in the therapeutic range (1.25-2.5 $\mathrm{mCi} / \mathrm{m}^{3}$ ) were evaluated. Among the 12 patients, only one patient had PR and 6 patients had stable disease. Necrotic tumors, which can be pathologically distinguished through features such as fibrinoid necrosis of blood vessel wall, white matter necrosis, and telangiectasis [88], were seen in several reoperated patients, which proved that Cotara has radiation effect on tumor, but its efficacy needs further evaluation.

\subsubsection{Immunomodulators}

Oligodeoxynucleotides Containing CpG Motifs (CpG-ODN) [74]. CpG-ODN is a strong immunomodulator, which activates both innate immunity (natural killing cells and macrophages) and adaptive immunity with the expectation of targeting tumor cells by the immune system. In the studies carried out by Carpentier et al. [63], CpG-ODN was infused at a rate of $0.2 \mathrm{~mL} / \mathrm{h}$ for 5 hours. The phase I study demonstrated a tolerated dose of $20 \mathrm{mg}$ [63]. In the following phase II trials, there was only one partial responder and three minor responders in 31 patients. Even worse, 13 patients out of 31 had treatment related seizure, among whom 3 had generalized seizure.

Overall, few efficacy studies demonstrated superior survivals over standard treatment regimen. Future investigations should adjust and standardize methodological parameters. Distribution volume prediction and validation should be implanted. Besides the above-mentioned reasons, another possible contributing factor for the failure of the clinical trials is related to the fact that CED augments the interstitial pressure, which could enhance the invasion of glioma cells [89].

\section{Discussion}

4.1. Choice of Agent. As we mentioned above, the advantages of CED compared with modern RT depend on the type of agents, i.e., those with different functions, such as 
targeted toxins, radiosensitizing chemotherapeutic agents, radioisotopes, and so on. CED of these agents aims to gain local control of tumor progression, as does RT, with a different approach, which includes tumor cell targeting and radiosensitization. A choice of a suitable agent can add valuable antitumor efficacy to traditional RT. Such agents should have the ability to selectively target the tumor cells in infiltrative areas and thus spare normal brain cells. In this case, higher local doses can be obtained in cancerous tissue compared to conventional RT, where toxicity of normal tissue is a major concern. In fact, the recurrent tumor usually emerges from the peritumoral area. When compared to recently developed immunotherapeutic methods, CED offers a novel approach for the application of those therapeutic agents to malignant gliomas $[94,95]$.

4.2. Treatment Planning. Under ideal conditions, the medical team planning clinical studies employing CED should be similar to that in charge of radiation treatments. In the latter, radiation oncologists delineate the gross tumor volume (GTV) based on CT scans and/or MRI, clinical targeting volume (CTV) 1 and 2 for high and low risk area and organs, respectively. They assign the treatment dose to each target volume restricting, as much as possible, the dose to organs at risk. Medical physicists or dosimetrists then calculate and design a treatment plan to meet the requirements of radiation oncologists. The dose planning is based on the angle and number of the radiation fields, CT value of the tissue, and so on. While in the future treatment planning for CED will first be based on MRI, many other parameters will have to be considered. These should include GTV, peritumoral area, organs at risk, such as brain stem, hippocampus, and other areas related to functions that influence the quality of life. Treatment would benefit from software, such as iPlan ${ }^{\circledR}$ Flow, based on the DW-MRI, probably with appropriate input parameters such as placement of catheters, surface charge and quantity of drug, viscosity of the infusate, and infusion rate and volume, to simulate the dose assigned for each CTV [96].

4.3. Monitoring the Distribution of the Infusate. After treatment planning and simulation, monitoring and validation of the placement of catheters and distribution of infusate are equally important. This procedure is again similar to RT; before each delivery we use cone beam computerized tomography (CBCT) system to ensure that the targeted tumor is positioned in the planned coordinates. For this purpose, many techniques have been investigated. Coinfusion of gadolinium with therapeutic agents is an easy approach to monitor the infusate distribution, assuming that gadolinium diffuses in the tumor in the same manner as the infusate [97-99]. Loading of gadolinium and drugs in the same vector, such as a liposome, represents another approach to monitoring the distribution [100, 101]. This approach has the advantage of revealing the "true image" of the drug distribution, as long as gadolinium does not leak due to the convection pressure. Methods that do not utilize additional gadolinium appear more attractive, but they may compromise the drug efficacy. Multivoxel ${ }^{1} \mathrm{H}$ MR Spectroscopy through analysis of metabolites ratio of $\mathrm{Cho} / \mathrm{Cr}$ and Cho/NAA is able to describe the tumor site with and without CED infusion [102], but the resolution of this technique needs to be increased for adequate analysis in the future. DW-MRI is another noninvasive approach that can monitor the response of CED delivery of Taxol [103]. The response can be detected within 24-48 hours with DWMRI, which is 1-2 days earlier than conventional imaging methods. However, none of the CED clinical trials assessed the distribution efficacy, which may be one of the factors that caused the failure of phase III clinical trial.

\section{Conclusion}

Regardless of emergence of novel therapeutic agents, their application in malignant gliomas remains rare, possibly due to the existence of the BBB. CED bypasses the BBB, increases the tumor uptake, and reduces the systemic toxicity. It has made progress during the past 25 years, since its invention, up to phase III clinical trial. It is a clinically feasible procedure with mostly local and tolerable toxicity, although grade III and IV adverse effects have been reported. Phase II clinical trials of PVSRIPO, Tf-diphtheria toxin, hold promise for future CED studies. Nevertheless, the phase III clinical trial failed to demonstrate survival improvements in the treatment of brain tumors. Analysis of the failure of these clinical trials showed the importance of catheter placement and distribution volume prediction and validation in performing CED treatments. Thus, it appears imperative to carefully analyze the methodological parameters to predict and validate the distribution volume for future clinical studies to be successful.

\section{Conflicts of Interest}

The authors declare that they have no conflicts of interest.

\section{Acknowledgments}

Minghan Shi would like to thank Dr. David Fortin for leading him to the field of CED. This review was supported in part by the Natural Science Foundation of Zhejiang Province under grant number LQ18H160013.

\section{References}

[1] S. I. Rapoport, M. Hori, and I. Klatzo, "Testing of a hypothesis for osmotic opening of the blood-brain barrier," American Journal of Physiology-Endocrinology and Metabolism, vol. 223, no. 2, pp. 323-331, 1972.

[2] E. A. Neuwelt, Implications of the Blood-Brain Barrier and Its Manipulation, vol. 1: Basic Science aspects, Springer, Boston, Mass, USA, 1989.

[3] D. Fortin, A. Desjardins, A. Benko, T. Niyonsega, and M. Boudrias, "Enhanced chemotherapy delivery by intraarterial infusion and blood-brain barrier disruption in malignant brain tumors: the Sherbrooke experience," Cancer, vol. 103, no. 12, pp. 2606-2615, 2005. 
[4] A. Carpentier, M. Canney, A. Vignot et al., "Clinical trial of blood-brain barrier disruption by pulsed ultrasound," Science Translational Medicine, vol. 8, no. 343, p. 343re2, 2016.

[5] R. Hunt Bobo, D. W. Laske, A. Akbasak, P. F. Morrison, R. L. Dedrick, and E. H. Oldfield, "Convection-enhanced delivery of macromolecules in the brain," Proceedings of the National Acadamy of Sciences of the United States of America, vol. 91, no. 6, pp. 2076-2080, 1994.

[6] E. Allard, C. Passirani, and J.-P. Benoit, "Convection-enhanced delivery of nanocarriers for the treatment of brain tumors," Biomaterials, vol. 30, no. 12, pp. 2302-2318, 2009.

[7] V. Y. Yu, A. Landers, K. Woods et al., "A prospective $4 \pi$ radiation therapy clinical study in recurrent high-grade glioma patients," nternational Journal of Radiation Oncology Biology Physics, vol. 101, no. 1, pp. 144-151, 2018.

[8] M. Shi, D. Fortin, L. Sanche, and B. Paquette, "Convectionenhancement delivery of platinum-based drugs and LipoplatinTM to optimize the concomitant effect with radiotherapy in F98 glioma rat model," Investigational New Drugs, vol. 33, no. 3 , pp. 555-563, 2015.

[9] P. Bernhardt, W. Friedland, and H. Paretzke, "The role of atomic inner shell relaxations for photon-induced DNA damage," Radiation and Environmental Biophysics, vol. 43, no. 2, pp. 7784, 2004.

[10] F. Theeuwes and S. I. Yum, "Principles of the design and operation of generic osmotic pumps for the delivery of semisolid or liquid drug formulations," Annals of Biomedical Engineering, vol. 4, no. 4, pp. 343-353, 1976.

[11] J. Rousseau, R. F. Barth, M. L. Moeschberger, and H. Elleaume, "Efficacy of intracerebral delivery of carboplatin in combination with photon irradiation for treatment of F98 glioma-bearing rats," International Journal of Radiation Oncology • Biology • Physics, vol. 73, no. 2, pp. 530-536, 2009.

[12] B. Sahin, H. Aslan, and B. Unal, "Brain volumes of the lamb, rat and bird do not show hemispheric asymmetry: a stereological study," Image Analysis \& Stereology, vol. 20, no. 1, p. 9, 2011.

[13] W. Yang, T. Huo, R. F. Barth et al., "Convection enhanced delivery of carboplatin in combination with radiotherapy for the treatment of brain tumors," Journal of Neuro-Oncology, vol. 101, no. 3, pp. 379-390, 2011.

[14] W. Debinski and S. B. Tatter, "Convection-enhanced delivery for the treatment of brain tumors," Expert Review of Neurotherapeutics, vol. 9, no. 10, pp. 1519-1527, 2014.

[15] P. F. Morrison, M. Y. Chen, R. S. Chadwick, R. R. Lonser, and E. H. Oldfield, "Focal delivery during direct infusion to brain: Role of flow rate, catheter diameter, and tissue mechanics," American Journal of Physiology-Regulatory, Integrative and Comparative Physiology, vol. 277, no. 4 Pt 2, pp. R1218-R1229, 1999.

[16] R. R. Lonser, S. Walbridge, K. Garmestani et al., "Successful and safe perfusion of the primate brainstem: in vivo magnetic resonance imaging of macromolecular distribution during infusion," Journal of Neurosurgery, vol. 97, no. 4, pp. 905-913, 2002.

[17] J. W. Degen, S. Walbridge, A. O. Vortmeyer, E. H. Oldfield, and R. R. Lonser, "Safety and efficacy of convection-enhanced delivery of gemcitabine or carboplatin in a malignant glioma model in rats," Journal of Neurosurgery, vol. 99, no. 5, pp. 893898, 2003.

[18] M. Y. Chen, R. R. Lonser, P. F. Morrison, L. S. Governale, and E. H. Oldfield, "Variables affecting convection-enhanced delivery to the striatum: a systematic examination of rate of infusion, cannula size, infusate concentration, and tissue - cannula sealing time," Journal of Neurosurgery, vol. 90, no. 2, pp. 315-320, 1999.

[19] M. T. Krauze, R. Saito, C. Noble et al., "Reflux-free cannula for convection-enhanced high-speed delivery of therapeutic agents," Journal of Neurosurgery, vol. 103, no. 5, pp. 923-929, 2005.

[20] M. Biston, A. Joubert, J. Adam et al., "Cure of fisher rats bearing radioresistant $\mathrm{F} 98$ glioma treated with cis-platinum and irradiated with monochromatic synchrotron X-rays," Cancer Research, vol. 64, no. 7, pp. 2317-2323, 2004.

[21] J. Rousseau, C. Boudou, R. F. Barth, J. Balosso, F. Esteve, and H. Elleaume, "Enhanced survival and cure of F98 glioma bearing rats following intracerebral delivery of carboplatin in combination with photon irradiation," Clinical Cancer Research, vol. 13, no. 17, pp. 5195-5201, 2007.

[22] M. T. Krauze, J. Forsayeth, D. Yin, and K. S. Bankiewicz, "Chapter 18 convection-enhanced delivery of liposomes to primate brain," Methods in Enzymology, vol. 465, no. C, pp. 349$362,2009$.

[23] A. A. Linninger, M. R. Somayaji, M. Mekarski, and L. Zhang, "Prediction of convection-enhanced drug delivery to the human brain," Journal of Theoretical Biology, vol. 250, no. 1, pp. 125-138, 2008.

[24] R. Raghavan, M. L. Brady, M. I. Rodríguez-Ponce, A. Hartlep, C. Pedain, and J. H. Sampson, "Convection-enhanced delivery of therapeutics for brain disease, and its optimization," Neurosurgical Focus, vol. 20, no. 4, p. E12, 2006.

[25] S. OH, R. Odland, S. R. Wilson et al., "Improved distribution of small molecules and viral vectors in the murine brain using a hollow fiber catheter," Journal of Neurosurgery, vol. 107, no. 3, pp. 568-577, 2007.

[26] S. B. Tatter, E. G. Shaw, M. L. Rosenblum et al., "An inflatable balloon catheter and liquid 125I radiation source (GliaSite Radiation Therapy System) for treatment of recurrent malignant glioma: multicenter safety and feasibility trial," Journal of Neurosurgery, vol. 99, no. 2, pp. 297-303, 2003.

[27] J. J. Olson, Z. Zhang, D. Dillehay, and J. Stubbs, “Assessment of a balloon-tipped catheter modified for intracerebral convectionenhanced delivery," Journal of Neuro-Oncology, vol. 89, no. 2, pp. 159-168, 2008.

[28] B. Halle, K. Mongelard, and F. Poulsen, "Convection-enhanced drug delivery for glioblastoma: a systematic review focused on methodological differences in the use of the convectionenhanced delivery method," Asian Journal of Neurosurgery, vol. 14, no. 1, pp. 5-14, 2019.

[29] R. Saito, J. R. Bringas, A. Panner et al., "Convection-enhanced delivery of tumor necrosis factor-related apoptosis-inducing ligand with systemic administration of temozolomide prolongs survival in an intracranial glioblastoma xenograft model," Cancer Research, vol. 64, no. 19, pp. 6858-6862, 2004.

[30] M. Nagane, G. Pan, J. J. Weddle, V. M. Dixit, W. K. Cavenee, and S. Huang, "Increased death receptor 5 expression by chemotherapeutic agents in human gliomas causes synergistic cytotoxicity with tumor necrosis factor- related apoptosis-inducing ligand in vitro and in vivo," Cancer Research, vol. 60, no. 4, pp. 847-853, 2000.

[31] G. M. Bernal, M. J. LaRiviere, N. Mansour et al., "Convectionenhanced delivery and in vivo imaging of polymeric nanoparticles for the treatment of malignant glioma," Nanomedicine: Nanotechnology, Biology and Medicine, vol. 10, no. 1, pp. 149-157, 2014. 
[32] T. Fourniols, L. D. Randolph, A. Staub et al., "Temozolomideloaded photopolymerizable PEG-DMA-based hydrogel for the treatment of glioblastoma," Journal of Controlled Release, vol. 210, pp. 95-104, 2015.

[33] M. M. Nordling-David, R. Yaffe, D. Guez et al., "Liposomal temozolomide drug delivery using convection enhanced delivery," Journal of Controlled Release, vol. 261, pp. 138-146, 2017.

[34] J. Rousseau, R. F. Barth, M. Fernandez et al., "Efficacy of intracerebral delivery of cisplatin in combination with photon irradiation for treatment of brain tumors," Journal of NeuroOncology, vol. 98, no. 3, pp. 287-295, 2010.

[35] R. F. Barth, W. Yang, T. Huo et al., "Comparison of intracerebral delivery of carboplatin and photon irradiation with an optimized regimen for boron neutron capture therapy of the F98 rat glioma," Applied Radiation and Isotopes, vol. 69, no. 12, pp. 1813-1816, 2011.

[36] W. Yang, R. F. Barth, T. Huo et al., "Radiation therapy combined with intracerebral administration of carboplatin for the treatment of brain tumors," Journal of Radiation Oncology, vol. 9, no. 1, p. 25, 2014.

[37] Y. Tange, A. Kondo, M. J. Egorin et al., "Interstitial continuous infusion therapy in a malignant glioma model in rats," Child's Nervous System, vol. 25, no. 6, pp. 655-662, 2009.

[38] M. Shi, D. Fortin, B. Paquette, and L. Sanche, "Convectionenhancement delivery of liposomal formulation of oxaliplatin shows less toxicity than oxaliplatin yet maintains a similar median survival time in F98 glioma-bearing rat model," Investigational New Drugs, vol. 34, no. 3, pp. 269-276, 2016.

[39] M. Shi, M. Anantha, M. Wehbe et al., "Liposomal formulations of carboplatin injected by convection-enhanced delivery increases the median survival time of F98 glioma bearing rats," Journal of Nanobiotechnology, vol. 16, no. 1, pp. 1-12, 2018.

[40] G. Charest, L. Sanche, D. Fortin, D. Mathieu, and B. Paquette, "Glioblastoma treatment: Bypassing the toxicity of platinum compounds by using liposomal formulation and increasing treatment efficiency with concomitant radiotherapy," International Journal of Radiation Oncology • Biology • Physics, vol. 84, no. 1, pp. 244-249, 2012.

[41] G. Charest, L. Sanche, D. Fortin, D. Mathieu, and B. Paquette, "Optimization of the route of platinum drugs administration to optimize the concomitant treatment with radiotherapy for glioblastoma implanted in the Fischer rat brain," Journal of Neuro-Oncology, vol. 115, no. 3, pp. 365-373, 2013.

[42] R. C. Richmond and E. L. Powers, "Radiation Sensitization of Bacterial Spores by cis-Dichlorodiammineplatinum(II)," Journal of Radiation Research, vol. 68, no. 2, pp. 251-257, 1976.

[43] E. B. Douple and R. C. Richmond, "Platinum complexes as radiosensitizers of hypoxic mammalian cells," The British Journal of Cancer, vol. 3, pp. 98-102, 1978.

[44] I. J. Stratford, C. Williamson, and G. E. Adams, "Combination studies with misonidazole and a cis-platinum complex: cytotoxicity and radiosensitization in vitro," British Journal of Cancer, vol. 41, no. 4, pp. 517-522, 1980.

[45] R. C. Richmond, A. R. Khokhar, B. A. Teicher, and E. B. Douple, "Toxic variability and radiation sensitization by $\mathrm{Pt}(\mathrm{II})$ analogs in salmonella typhimurium cells," Journal of Radiation Research, vol. 99, no. 3, pp. 609-626, 1984.

[46] A. Dritschilo, A. J. Piro, and A. D. Kelman, "The effect of cis-platinum on the repair of radiation damage in plateau phase CHINESE hamster (V-79) cells," International Journal of Radiation Oncology • Biology • Physics, vol. 5, no. 8, pp. 13451349, 1979.
[47] L. Dewit, "Combined treatment of radiation and cisdiamminedichloroplatinum (II): a review of experimental and clinical data," International Journal of Radiation Oncology • Biology• Physics, vol. 13, no. 3, pp. 403-426, 1987.

[48] L. Yang, E. B. Douple, and H. Wang, "Irradiation enhances cellular uptake of carboplatin," International Journal of Radiation Oncology • Biology • Physics, vol. 33, no. 3, pp. 641-646, 1995.

[49] J. Kopyra, C. Koenig-Lehmann, I. Bald, and E. Illenberger, "A single slow electron triggers the loss of both chlorine atoms from the anticancer drug cisplatin: implications for chemoradiation therapy," Angewandte Chemie International Edition, vol. 48, no. 42, pp. 7904-7907, 2009.

[50] B. Behmand, J. R. Wagner, L. Sanche, and D. J. Hunting, "Cisplatin intrastrand adducts sensitize DNA to base damage by hydrated electrons," The Journal of Physical Chemistry B, vol. 118, no. 18, pp. 4803-4808, 2014.

[51] Y. Zheng, D. J. Hunting, P. Ayotte, and L. Sanche, "Role of secondary low-energy electrons in the concomitant chemoradiation therapy of cancer," Physical Review Letters, vol. 100, no. 19, pp. 1-4, 2008.

[52] M. Rezaee, D. J. Hunting, and L. Sanche, "New insights into the mechanism underlying the synergistic action of ionizing radiation with platinum chemotherapeutic drugs: The role of low-energy electrons," International Journal of Radiation Oncology • Biology • Physics, vol. 87, no. 4, pp. 847-853, 2013.

[53] Z. Li, P. Cloutier, L. Sanche, and J. R. Wagner, "Low-energy electron-induced damage in a trinucleotide containing 5bromouracil," The Journal of Physical Chemistry B, vol. 115, no. 46, pp. 13668-13673, 2011.

[54] Q. Bao, Y. Chen, Y. Zheng, and L. Sanche, "Cisplatin radiosensitization of DNA irradiated with $2-20 \mathrm{eV}$ electrons: role of transient anions," The Journal of Physical Chemistry C, vol. 118, no. 28, pp. 15516-15524, 2014.

[55] T. Tippayamontri, R. Kotb, B. Paquette, and L. Sanche, "Efficacy of cisplatin and lipoplatin ${ }^{\mathrm{TM}}$ in combined treatment with radiation of a colorectal tumor in nude mouse," Anticancer Reseach, vol. 33, no. 8, pp. 3005-3014, 2013.

[56] T. Tippayamontri, R. Kotb, B. Paquette, and L. Sanche, "New therapeutic possibilities of combined treatment of radiotherapy with oxaliplatin and its liposomal formulations (LipoxalTM) in colorectal cancer using nude mouse xenograft," Anticancer Research, vol. 5312, pp. 5303-5312, 2014.

[57] S. Kunwar, S. Chang, M. Westphal et al., "Phase III randomized trial of CED of IL13-PE38QQR vs Gliadel wafers for recurrent glioblastoma," Neuro-Oncology, vol. 12, no. 8, pp. 871-881, 2010.

[58] H. Ren, T. Boulikas, K. Lundstrom, A. Söling, P. C. Warnke, and N. G. Rainov, "Immunogene therapy of recurrent glioblastoma multiforme with a liposomally encapsulated replicationincompetent Semliki forest virus vector carrying the human interleukin-12 gene-a phase I/II clinical protocol," Journal of Neuro-Oncology, vol. 64, no. 1-2, pp. 147-154, 2003.

[59] E. White, A. Bienemann, J. Pugh et al., "An evaluation of the safety and feasibility of convection-enhanced delivery of carboplatin into the white matter as a potential treatment for high-grade glioma," Journal of Neuro-Oncology, vol. 108, no. 1, pp. 77-88, 2012.

[60] P. Wersäll, I. Ohlsson, P. Biberfeld et al., "Intratumoral infusion of the monoclonal antibody, mAb 425, against the epidermalgrowth-factor receptor in patients with advanced malignant glioma," Cancer Immunology, Immunotherapy, vol. 44, no. 3, pp. 157-164, 1997. 
[61] S. Kunwar, S. M. Chang, M. D. Prados et al., "Safety of intraparenchymal convection-enhanced delivery of cintredekin besudotox in early-phase studies," Neurosurgical Focus, vol. 20, no. 3, p. E15, 2006.

[62] J. Voges, R. Reszka, A. Gossmann et al., "Imaging-guided convection-enhanced delivery and gene therapy of glioblastoma," Annals of Neurology, vol. 54, no. 4, pp. 479-487, 2003.

[63] A. Carpentier, F. Laigle-Donadey, S. Zohar et al., "Phase 1 trial of a CpG oligodeoxynucleotide for patients with recurrent gliobastoma," Neuro-Oncology, vol. 8, no. 1, pp. 60-66, 2006.

[64] D. W. Laske, R. J. Youle, and E. H. Oldfield, "Tumor regression with regional distribution of the targeted toxin TF- CRM107 in patients with malignant brain tumors," Nature Medicine, vol. 3, no. 12, pp. 1362-1368, 1997.

[65] R. W. Rand, R. J. Kreitman, N. Patronas, F. Varricchio, I. Pastan, and R. K. Puri, "Intratumoral administration of recombinant circularly permuted interleukin-4-Pseudomonas exotoxin in patients with high-grade glioma," Clinical Cancer Research, vol. 6, no. 6, pp. 2157-2165, 2000.

[66] F. Weber, A. L. Asher, R. Bucholz et al., "Tolerability and tumor response of IL4-toxin (NBI-3001) in patients with recurrent malignant glioma," Neurosurgery, vol. 49, no. 2, p. 525, 2001.

[67] Z. Lidar, Y. Mardor, T. Jonas et al., "Convection-enhanced delivery of paclitaxel for the treatment of recurrent malignant glioma: a phase I/II clinical study," Journal of Neurosurgery, vol. 100, no. 3, pp. 472-479, 2004.

[68] S. Kunvvar, "Convection enhanced delivery of IL13-PE38QQR for treatment of recurrent malignant glioma: Presentation of interim findings from ongoing phase 1 studies," Acta $\mathrm{Neu}$ rochirurgica, Supplementum, no. 88, pp. 105-111, 2003.

[69] G. Pöpperl, R. Goldbrunner, F. J. Gildehaus et al., "O-(2[18F]fluoroethyl)-l-tyrosine PET for monitoring the effects of convection-enhanced delivery of paclitaxel in patients with recurrent glioblastoma," European Journal of Nuclear Medicine and Molecular Imaging, vol. 32, no. 9, pp. 1018-1025, 2005.

[70] M. Weaver and D. W. Laske, "Transferrin receptor ligandtargeted toxin conjugate (Tf-CRM107) therapy of malignant gliomas," Journal of Neuro-Oncology, vol. 65, no. 1, pp. 3-13, 2003.

[71] D. Klatzmann, C. A. Valéry, G. Bensimon et al., "A phase I/II study of herpes simplex virus type 1 thymidine kinase 'Suicide' gene therapy for recurrent glioblastoma," Human Gene Therapy, vol. 9, no. 17, pp. 2595-2604, 1998.

[72] P. G. Tanner, M. Holtmannspötter, J. Tonn, and R. Goldbrunner, "Effects of drug efflux on convection-enhanced paclitaxel delivery to malignant gliomas: technical note," Neurosurgery, vol. 61, no. 4, pp. E880-E882, 2007.

[73] A. Boiardi, M. Eoli, A. Salmaggi et al., "Local drug delivery in recurrent malignant gliomas," Neurological Sciences, vol. 26, no. S1, pp. s37-s39, 2005.

[74] A. Carpentier, P. Metellus, R. Ursu et al., "Intracerebral administration of $\mathrm{CpG}$ oligonucleotide for patients with recurrent glioblastoma: a phase II study," Neuro-Oncology, vol. 12, no. 4, pp. 401-408, 2010.

[75] U. Bogdahn, P. Hau, G. Stockhammer et al., "Targeted therapy for high-grade glioma with the TGF- $\beta 2$ inhibitor trabedersen: results of a randomized and controlled phase IIb study," NeuroOncology, vol. 13, no. 1, pp. 132-142, 2011.

[76] S. J. Patel, W. R. Shapiro, D. W. Laske et al., "Safety and feasibility of convection-enhanced delivery of Cotara for the treatment of malignant glioma: Initial experience in 51 patients," Neurosurgery, vol. 56, no. 6, pp. 1243-1252, 2005.
[77] M. M. Souweidane, K. Kramer, N. Pandit-Taskar et al., "Convection-enhanced delivery for diffuse intrinsic pontine glioma: a single-centre, dose-escalation, phase 1 trial," The Lancet Oncology, vol. 19, no. 8, pp. 1040-1050, 2018.

[78] J. N. Bruce, R. L. Fine, P. Canoll et al., "Regression of recurrent malignant gliomas with convection-enhanced delivery of topotecan," Neurosurgery, vol. 69, no. 6, pp. 1272-1280, 2011.

[79] A. Jahangiri, A. T. Chin, P. M. Flanigan, R. Chen, K. Bankiewicz, and M. K. Aghi, "Convection-enhanced delivery in glioblastoma: a review of preclinical and clinical studies," Journal of Neurosurgery, vol. 126, no. 1, pp. 191-200, 2017.

[80] S. Kunwar, M. D. Prados, S. M. Chang et al., "Direct intracerebral delivery of cintredekin besudotox (IL13-PE38QQR) in recurrent malignant glioma: a report by the cintredekin besudotox intraparenchymal study group," Journal of Clinical Oncology, vol. 25, no. 7, pp. 837-844, 2007.

[81] M. A. Vogelbaum, J. H. Sampson, S. Kunwar et al., "Convectionenhanced delivery of cintredekin besudotox (interleukin-13PE38QQR) followed by radiation therapy with and without temozolomide in newly diagnosed malignant gliomas: phase 1 study of final safety results," Neurosurgery, vol. 61, no. 5, pp. 10311038, 2007.

[82] J. H. Sampson, G. Archer, C. Pedain et al., "Poor drug distribution as a possible explanation for the results of the PRECISE trial," Journal of Neurosurgery, vol. 113, no. 2, pp. 301-309, 2010.

[83] Z. Ram, K. W. Culver, E. M. Oshiro et al., "Therapy of malignant brain tumors by intratumoral implantation of retroviral vectorproducing cells," Nature Medicine, vol. 3, no. 12, pp. 1354-1361, 1997.

[84] N. G. Rainov, "A phase III clinical evaluation of herpes simplex virus type 1 thymidine kinase and ganciclovir gene therapy as an adjuvant to surgical resection and radiation in adults with previously untreated glioblastoma multiforme," Human Gene Therapy, vol. 11, no. 17, pp. 2389-2401, 2000.

[85] N. Shand, F. Weber, L. Mariani et al., "A phase 1-2 clinical trial of gene therapy for recurrent glioblastoma multiforme by tumor transduction with the herpes simplex thymidine kinase gene followed by ganciclovir," Human Gene Therapy, vol. 10, no. 14, pp. 2325-2335, 1999.

[86] P. Hau, P. Jachimczak, R. Schlingensiepen et al., "Inhibition of TGF-beta2 with AP 12009 in recurrent malignant gliomas: from preclinical to phase I/II studies," Oligonucleotides, vol. 17, no. 2, pp. 201-212, 2007.

[87] A. Desjardins, M. Gromeier, J. E. Herndon et al., "Recurrent glioblastoma treated with recombinant poliovirus," The New England Journal of Medicine, vol. 379, no. 2, pp. 150-161, 2018.

[88] A. Na, N. Haghigi, and K. J. Drummond, "Cerebral radiation necrosis," Asia-Pacific Journal of Clinical Oncology, vol. 10, no. 1, pp. 11-21, 2014.

[89] J. M. Munson, R. V. Bellamkonda, and M. A. Swartz, "Interstitial flow in a $3 \mathrm{D}$ microenvironment increases glioma invasion by a CXCR4-dependent mechanism," Cancer Research, vol. 73, no. 5, pp. 1536-1546, 2013.

[90] F. W. Weber, F. Floeth, A. Asher et al., "Local convection enhanced delivery of IL4-Pseudomonas exotoxin (NBI-3001) for treatment of patients with recurrent malignant glioma," Acta Neurochirurgica, vol. 88, pp. 93-103, 2003.

[91] J. H. Sampson, G. Akabani, G. E. Archer et al., "Progress report of a Phase I study of the intracerebral microinfusion of a recombinant chimeric protein composed of transforming growth factor (TGF)- $\alpha$ and a mutated form of the Pseudomonas 
exotoxin termed PE-38 (TP-38) for the treatment of malignant brain," Journal of Neuro-Oncology, vol. 65, no. 1, pp. 27-35, 2003.

[92] J. H. Sampson, G. Akabani, G. E. Archer et al., "Intracerebral infusion of an EGFR-targeted toxin in recurrent malignant brain tumors," Neuro-Oncology, vol. 10, no. 3, pp. 320-329, 2008.

[93] J. H. Sampson, G. Akabani, A. H. Friedman et al., "Comparison of intratumoral bolus injection and convection-enhanced delivery of radiolabeled antitenascin monoclonal antibodies," Neurosurgical Focus, vol. 20, no. 4, p. E14, 2006.

[94] N. Hilf, S. Kuttruff-Coqui, K. Frenzel et al., "Actively personalized vaccination trial for newly diagnosed glioblastoma," Nature, vol. 565, no. 7738, pp. 240-245, 2019.

[95] D. B. Keskin, A. J. Anandappa, J. Sun et al., "Neoantigen vaccine generates intratumoral $\mathrm{T}$ cell responses in phase Ib glioblastoma trial," Nature, vol. 565, no. 7738, pp. 234-239, 2019.

[96] j. H. Sampson, R. Raghavan, M. L. Brady et al., "Clinical utility of a patient-specific algorithm for simulating intracerebral drug infusions," Neuro-Oncology, vol. 9, no. 3, pp. 343-353, 2007.

[97] N. Sharma, K. S. Bankiewicz, M. T. Krauze et al., "Image-guided convection-enhanced delivery of GDNF protein into monkey putamen," NeuroImage, vol. 54, pp. S189-S195, 2011.

[98] J. H. Sampson, M. Brady, R. Raghavan et al., "Colocalization of gadolinium-diethylene triamine pentaacetic acid with highmolecular-weight molecules after intracerebral convectionenhanced delivery in humans," Neurosurgery, vol. 69, no. 3, pp. 668-676, 2011.

[99] M. Watanabe, T. Kumabe, R. Saito, K. Nagamatsu, T. Tominaga, and Y. Sonoda, "Regression of recurrent glioblastoma infiltrating the brainstem after convection-enhanced delivery of nimustine hydrochloride," Journal of Neurosurgery: Pediatrics, vol. 7, no. May, pp. 522-526, 2016.

[100] M. T. Krauze, T. R. Mcknight, Y. Yamashita et al., "Real-time visualization and characterization of liposomal delivery into the monkey brain by magnetic resonance imaging," Brain Research Protocols, vol. 16, no. 1-3, pp. 20-26, 2005.

[101] M. T. Krauze, J. Forsayeth, J. W. Park, and K. S. Bankiewicz, "Real-time Imaging and Quantification of Brain Delivery of Liposomes," Pharmaceutical Research, vol. 23, no. 11, pp. 24932504, 2006.

[102] D. I. Guisado, R. Singh, S. Minkowitz et al., "A novel methodology for applying multivoxel MR spectroscopy to evaluate convection-enhanced drug delivery in diffuse intrinsic pontine gliomas," American Journal of Neuroradiology, vol. 37, no. 7, pp. 1367-1373, 2016.

[103] Y. Mardor, Y. Roth, A. Orenstein et al., "Monitoring response to convection-enhanced taxol delivery in brain tumor patients using diffusion-weighted magnetic resonance imaging," Cancer Research, vol. 61, no. 13, pp. 4971-4973, 2001. 


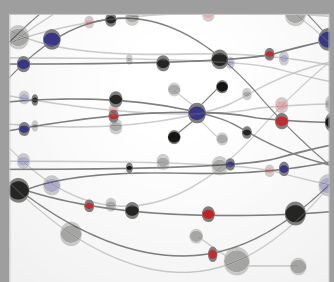

The Scientific World Journal
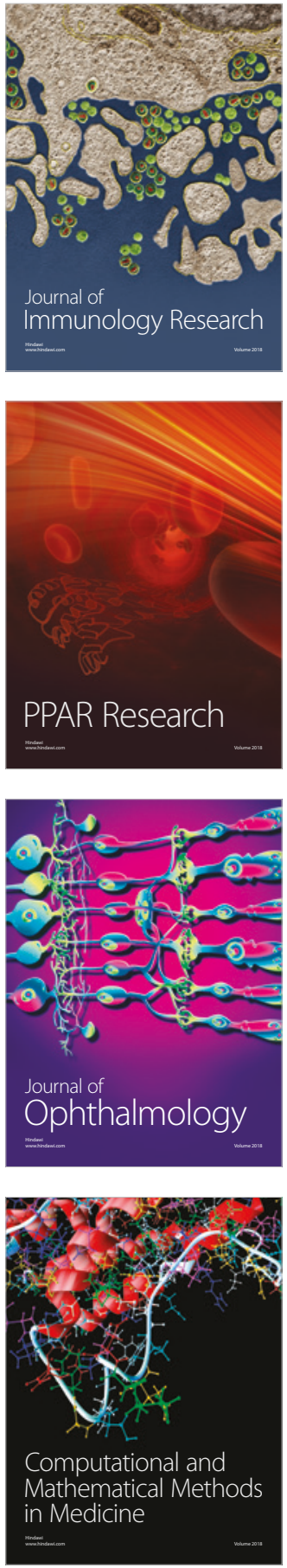

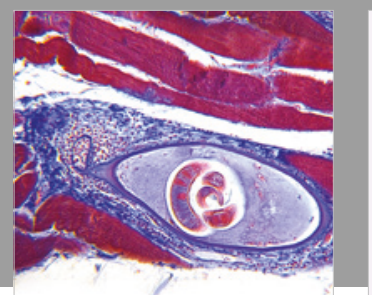

Gastroenterology Research and Practice

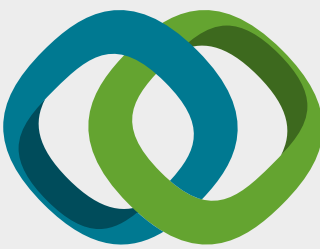

\section{Hindawi}

Submit your manuscripts at

www.hindawi.com
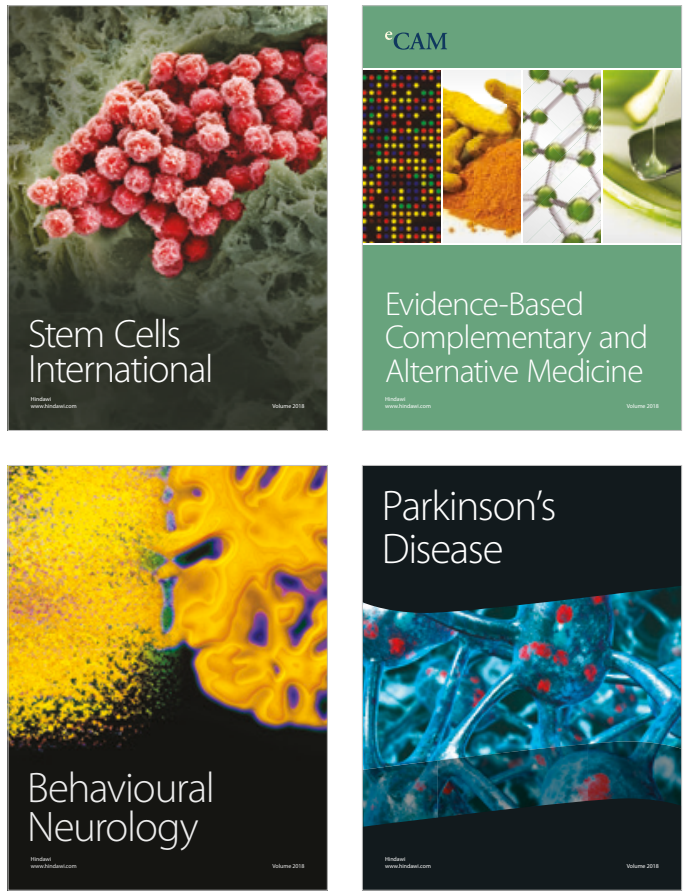

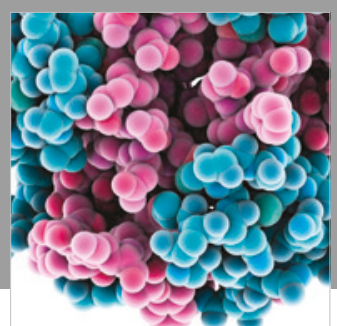

ournal of

Diabetes Research

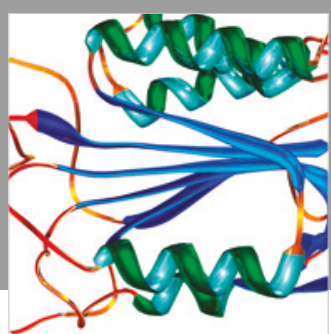

Disease Markers
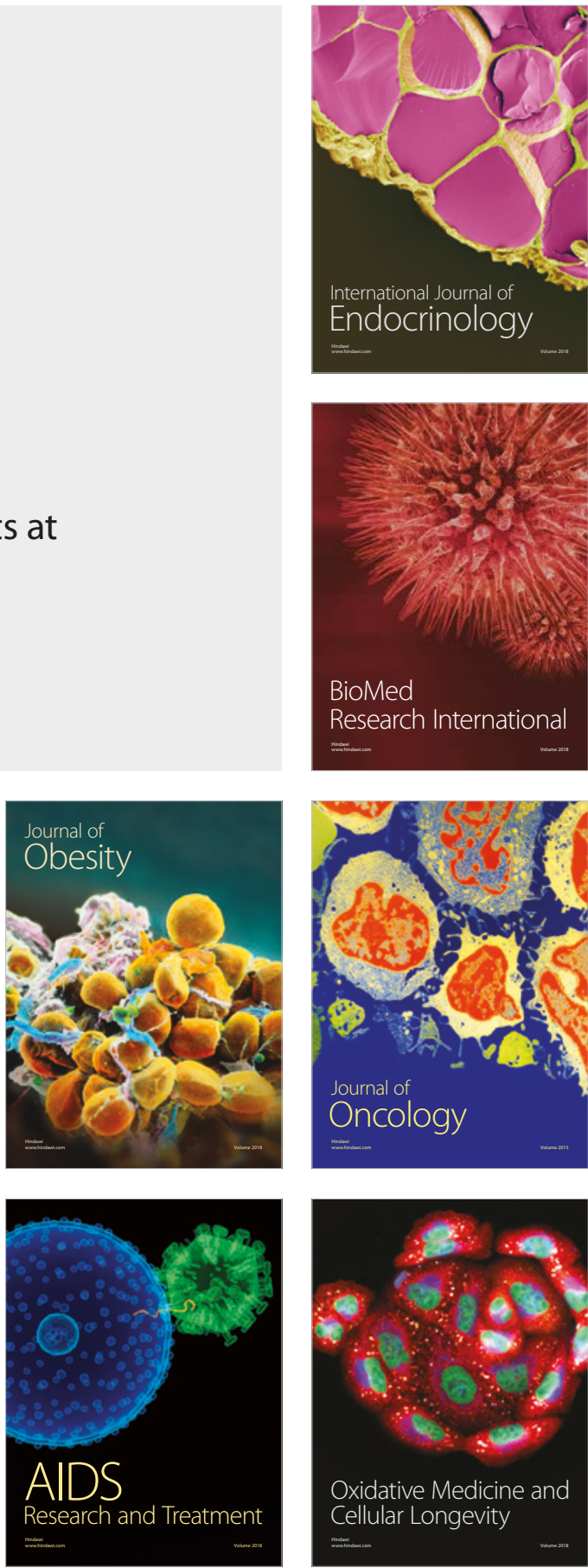